\title{
Pharmacological Correction of Early Embryogenesis Disorders in Cows
}

\section{Vitaly Ivanovich Mikhalev ${ }^{1}$, Sergey Viktorovich Shabunin ${ }^{\mathbf{1}}$, Yury Anatolyevich Vatnikov ${ }^{2}$, Sergey Borisovich Seleznev ${ }^{2}$, Evgeny Vladimirovich Kulikov ${ }^{2}$, Valentina Ivanovna Parshina $^{2}$, Irina Anatolyevna Popova ${ }^{2 *}$, Victor Nikolaevich Grishin ${ }^{2}$, Natalia Igorevna TroshinA ${ }^{2}$}

${ }^{1}$ All-Russian Veterinary Research Institute of Pathology, Pharmacology and Therapy, st.Lomonosova, 114B, Voronezh, 394087; 'Peoples' Friendship University of Russia (RUDN University), Moscow, st.Miklukbo-Maklaya, 6, 117198.

\begin{abstract}
Materials on the study of progestogenic, gonadotropic, selenium-containing and immunocorrective agents' effectiveness for the prevention of fetal development disorders in cows are present in the article. The aim of the research: is to study of pharmacological agents effectiveness for the prevention of early embryogenesis disorders in cows. Materials and methods: The studies were carried out on black-and-white cows with an average annual milk production of 5.5-7.5 thousand $\mathrm{kg}$ with tie-up and yard housing at various times after calving. Efficacy evaluation of methods for preventing intrauterine growth retardation and mortality of embryos and fetuses was carried out at 30-32 and 60-65 days after insemination by ultrasound. Diagnosis of intrauterine growth retardation syndrome of the embryo and fetus in cows was carried out retrospectively. The results of the study: The prophylactic efficacy of progestagam was $60.0 \%$, follymag combined with selemag $-61.5 \%$, and bovine recombinant interferon-tau - $66.7 \%$. Pregnancy after the application of these preparations proceeds against the background of increased content of progesterone (higher by 16.4-52.2\%), which favorably affects the development of the embryo and fetus, the length of which in the first two months of gestation is $35.8-56.9 \%$ more than intact animals. Conclusion: The most effective ways of preventing early embryogenesis disorders (fetal death, embryo and fetal growth retardation syndrome) are the use of progestogenic and gonadotropic drugs, as well as interferon-series drugs - interferon-tau.
\end{abstract}

Keywords | Cows, Fetal death, Prevention, Progesterone, Interferon-tau.

Received | March 18, 2019; Accepted | June 29, 2019; Published | August 24, 2019

*Correspondence | Irina Anatolyevna Popova, Peoples' Friendship University of Russia (RUDN University), Moscow, st.Miklukho-Maklaya, 6, 117198; Email: ir.popova94@gmail.com

Citation | Mikhalev VI, Shabunin SV, Vatnikov YA, Seleznev SB, Kulikov EV, Parshina VI, Popova IA, Grishin VN, Troshina NI (2019). Pharmacological correction of early embryogenesis disorders in cows. Adv. Anim. Vet. Sci. 7(9): 749-754.

DOI | http://dx.doi.org/10.17582/journal.aavs/2019/7.9.749.754

ISSN (Online) | 2307-8316; ISSN (Print) | 2309-3331

Copyright (C) 2019 Popova et al. This is an open access article distributed under the Creative Commons Attribution License, which permits unrestricted use, distribution, and reproduction in any medium, provided the original work is properly cited.

\section{INTRODUCTION}

$\mathrm{I}^{\mathrm{n}}$ connection with the breeding of highly productive livestock and the introduction of various biotechnological methods of its programmed reproduction, the problem of intrauterine embryo death is currently of particular relevance due to the large economic losses associated with reduced fertility and milk production (Bonadonna, 1969; Milovanov and Sokolovskaya, 1984; Lenchenko et al., 2007; Shirasuna et al., 2015). At the same time, embryonic mortality, reaching $30-40 \%$ or more, is the domi- nant reason for reducing the intensive development of the dairy cattle breeding industry and its profitability (Spencer, 2007; Dulger, 2012; Chaudhary and Purohit, 2012; Brooks et al., 2014).

Pathology of pregnancy takes an important place in the structure of antenatal (intrauterine) mortality causes in cows, defined in scientific literature and clinical practice as anintrauterine embryo and fetal growth retardation syndrome (IGR), manifested by a discrepancy in their size to the gestation period. According to literature data, 
it is registered in 34.4-37.6\% of cows (Tefera et al., 2001; Zhao et al., 2008). The manifestation of this syndrome has a negative effect not only on fetal survival, but also on the viability of newborns, on the morphofunctional development of their organs and systems of digestion, respiration and reproduction, on metabolism and endocrine system, and also reduced fertility and productivity (Demmers et al., 2001; Wu et al., 2006; Lenchenko et al., 2017; Suleymanov et al., 2018).

In the polyfactorial etiology of early embryo death and developmental delay, oxidizing stress, metabolic intoxication and the associated endocrine insufficiency of the sex glands and hypoprogesteronemia act as determining factors ( $\mathrm{Sa}-$ fonov, 2011; Lyalichkina et al., 2012; Spenser and Hanser, 2015; Basavaraja et al., 2017; Ealy and Wooldridge, 2017). Existing methods for preventing embryonic mortality are based on compensating the deficit in the body of inseminated animals with progesterone by its subcutaneous administration or by activating its endogenous synthesis with injections of gonadoliberins or gonadotropins (Klinsky et al., 1987; Chomaev and Kolodiev, 2003; Baitlesov, 2007; Romano et al., 2007).

In this regard, the issue of developing new and improving existing methods of preventing embryonic development disorders in cows is of particular relevance.

\section{The Aim of Research}

To study the effectiveness of pharmacological agents (progesterone, progestag, follymag, selemag, interferon-tau) for the prevention of early embryogenesis disorders in cows.

\section{MATERIAL AND METHODS}

The studies were carried out in 2018 under in OOO VS (village settlement) Vyaznovatovka (Nizhnedevitsky District, Voronezh Region) and ZAO Slavyanskoe (Verkhovsky District, Oryol Region) on black-and-white cows with an average annual milk production of 5.5-7.5 thousand $\mathrm{kg}$ with tie-up and yard housing at various times after calving. The study of the effectiveness of methods for the prevention of fetal mortality and fetal developmental delay was carried out on 81 cows, divided according to the principle of analogues into six groups.

The cows of the first group ( $\mathrm{n}=13)$ were intramuscularly injected with $2.5 \%$ progesterone oil solutionat $5-6$ and $12-$ 14 days after insemination at a dose of $4 \mathrm{ml}$.

Animals of the second group $(\mathrm{n}=15)$ were injected intramuscularly with the drug progestamag at 5-6 and 12-14 days after insemination at a dose of $2 \mathrm{ml}$.
The third group of cows $(n=11)$ was injected with follymag for 1-3 days after insemination once a dose of $750 \mathrm{IU}$. Fourth group animals $(n=13)$ were injected with follymag for 1-3 days after insemination once at a dose of $750 \mathrm{IU}$ and selemag twice: at the day of insemination and for 1214 days after insemination at a dose of $5 \mathrm{ml} / 100 \mathrm{~kg}$ body weight.

Cows of the fifth group $(n=12)$ were injected with bovine recombinant interferon-tau three times between 12-14-16 days after insemination, $5 \mathrm{ml}$ each.

Animals of the sixth group $(n=17)$ served as negative control - without drug administration.

Evaluation of the effectiveness of methods for preventing intrauterine growth retardation and mortality of embryos and fetuses was carried out at 30-32 and 60-65 days after insemination by ultrasound. Ultrasound studies were performed using an EasyScan scanner equipped with a 7.5 $\mathrm{MHz}$ linear sensor.

The diagnosis of embryonic losses was carried out by transrectal echographic examination of cows in the dynamics of becoming pregnant: for 38-45 days - the presence of an embryo in the cavity of the uterus and its absence in 60-65 days of pregnancy.

Diagnosis of intrauterine growth retardation syndrome in cows was carried out retrospectively. During ultrasound scanning and determination of fetometric indicators for 38-40 days of gestation, the embryo's length is within 12$16 \mathrm{~mm}$ and the body diameter is 7-9 $\mathrm{mm}$ or for 60-65 days - the length of the fetus is within $25-45 \mathrm{~mm}$ and the body diameter is $12-16 \mathrm{~mm}$, was diagnosed with the syndrome of embryo and fetus delayed developmentin cows (Hansen et al., 2017).

Blood samples were taken from animals included in the experiment for morphological, biochemical and immunological studies. Hemomorphological blood analysis was performed on a ABX Micros 60 hematology analyzer, biochemical studies were performed on a Hitachi-902 analyzer, in accordance with the Methodological Guidelines for the Use of Biochemical Methods for Examining the Blood of Animals (Retzky et al., 2005). Immunological parameters, including bactericidal (BSA), lysozyme (LSA) serum activity, total immunoglobulins, circulating immune complexes, phagocytic activity of leukocytes (PAL), phagocytic number (PN), phagocytic index (PI) were determined using standard and unified methods in in accordance with the Guidelines for the evaluation and correction of the immune status of animals (Shakhov et al., 2005).

The content of progesterone in the serum was determined 
on the day of insemination and on the 38th to 45th day of gestation with the use of reagents for the enzyme immunoassay for the determination of progesterone in the serum (ZAO NVO Immunotech).

The digital material was subjected to mathematical processing using the software package Statistica 6.0.

\section{RESULTS AND DISCUSSION}

Under the physiological conditions of embryo formation, progesterone levels sufficient to support the implantation processes are provided by the production of trophectoderm of the interferon-tau embryo, which has anti-luteolytic properties through the suppression of estrogen receptors and oxytocin in the endometrium and the blockade of prostaglandin F2 $\alpha$ production (Lamming et al., 1995; Demmers et al., 2001; Basavaraja et al., 2017; Ealyand Wooldridge, 2017; Imakawa et al., 2017; Seleznev et al 2017). Interferon-tau allows female ruminants to receive a signal about the presence of pregnancy. The maximum concentration of interferon-tau in ruminants reaches on the 17th day of pregnancy, and then decreases by $20-22$ days (Spencer, 2007; Kose et al., 2016; Forde and Lonergan, 2017).

Prevention of early embryogenesis disorders in cows was carried out using the following pharmacological agents: progesterone oil solution, progestag, follymag, selenium containing oil - selemag, and bovine recombinant interferon-tau.

It was revealed (Table 1) that in the negative control group, fetal growth retardation syndrome was registered in 33.3\% of fertilized cows, intrauterine death - in $16.7 \%$. The use of progesterone oil solution is accompanied by a decrease in embryonic mortality by 1.2 times and a syndrome of delayed development of the embryo and fetus - by 2.3 times. A higher preventive efficacy (60.0\%) showed a method using a prolonged form of progesterone, a progestag, the use of which is accompanied by the absence of cases of intrauterine embryo death and a reduction in fetal growth retardation syndrome by 3.0 times.

The use of gonadotropic follymag is accompanied by a decrease in embryonic mortality by 1.8 times and fetal growth retardation syndrome - by 3.7 times. Improving the effectiveness of gonadotropic drugs is provided by the additional inclusion in the scheme of prevention of selenium-containing drug selemag. The combined use of follymag and selemag provides an efficiency of $61.5 \%$.

The most effective was the use of bovine recombinant interferon-tau $-66.7 \%$. Three-time introduction of interferon-tau reduces the cases of intrauterine embryo death by
1.5 times compared with the negative control and the syndrome of delayed development - 3.0 times.

It should be noted that methods of preventing early embryogenesis disorders in cows using the prolonged form of progesterone - progestamag, bovine recombinant interferon-tau, or the combined use of the gonadotropic drug follymag and selenium-containing medication were most effective.

The results of clinical studies were confirmed by data on the study of the level of progesterone in serum before and after the use of pharmacological agents in order to prevent embryonic development disorders (Table 2).

It was established that in the negative control group, the content of progesterone by 30-45 days of gestation increases by 30.5 times as compared with the first day of insemination.

At the same time, after applying progesterone oil solution, its concentration in $38-45$ days of gestation is $16.4 \%$ higher compared with animals from the negative control group.

Pregnancy after the application of the prolonged progestamag proceeds against the background of an increased content of progesterone, the level of which is $11.9 \%$ higher than after a double injection of the progesterone oil solutionand $30.3 \%(\mathrm{P}<0.01)$ than in intact animals. After applying follymag and selemag, the content of progesterone is higher by $19.7 \%$ compared to the cows from the negative control group. The highest concentration of progesterone in the first 1.5 months of pregnancy was after using bovine recombinant interferon-tau, which is $52.2 \%$ higher than that of intact animals.

Thus, pregnancy after the use of progestogenic and gonadotropic drugs, as well as interferons, proceeds against the background of an elevated progesterone level in serum. The progesterone level reaches to $16.4-52.2 \%$ higher in comparison with animals from the negative control group.

Differences in the content of progesterone in the blood serum of cows in the application of methods for preventing disorders of embryonic development were reflected in the results of echographic studies of the size of the corpus luteum, the length of the embryo and fetus in the first two months of pregnancy (Table 3 ).

It has been established that double application of progesterone oil solution contributes to an increase in the size of the corpus luteum gestation, which in 30-32 days of gestation exceed the same compared to intact animals by $18.7 \%$ $(\mathrm{P}<0.05)$, and in $60-65$ days - by $21.8 \%$. 
Table 1: The effectiveness of methods for the pharmacological correction of early embryogenesis disorders in cows

\begin{tabular}{|c|c|c|c|c|c|c|c|c|}
\hline \multirow[t]{2}{*}{ Group } & \multirow[t]{2}{*}{$\begin{array}{l}\text { Number } \\
\text { of cows }\end{array}$} & \multicolumn{2}{|c|}{ Fertilized } & \multicolumn{2}{|c|}{$\begin{array}{l}\text { Intrauterine } \\
\text { death }\end{array}$} & \multicolumn{2}{|c|}{$\begin{array}{l}\text { Fetal developmental } \\
\text { delay syndrome }\end{array}$} & \multirow[t]{2}{*}{ Stayed pregnant $\%$} \\
\hline & & cows & $\%$ & cows & $\%$ & cows & $\%$ & \\
\hline 1 group & 13 & 7 & 53,8 & 1 & 14,3 & 1 & 14,3 & 46,2 \\
\hline 2group & 15 & 9 & 60,0 & 0 & 0,0 & 1 & 11,1 & 60,0 \\
\hline 3 group & 11 & 6 & 54,5 & 1 & 9,1 & 1 & 9,1 & 45,5 \\
\hline 4 group & 13 & 8 & 61,5 & 0 & 0,0 & 2 & 25,0 & 61,5 \\
\hline 5 group & 12 & 9 & 75,0 & 1 & 11,1 & 1 & 11,1 & 66,7 \\
\hline 6 group & 17 & 6 & 35,3 & 1 & 16,7 & 2 & 33,3 & 29,4 \\
\hline
\end{tabular}

Table 2: The content of progesterone in the blood serum of cows in the prevention of fetal development disorders, $\mathrm{nmol} / \mathrm{l}$

\begin{tabular}{lll} 
Group & $\begin{array}{l}\text { Days of pregnancy } \\
\text { Insemination day }\end{array}$ & $\mathbf{3 8 - 4 5}$ \\
\hline 1 group & $1,17 \pm 0,08$ & $41,9 \pm 1,9$ \\
\hline group & $0,88 \pm 0,06$ & $46,9 \pm 2,6^{* *}$ \\
\hline group & $0,95 \pm 0,09$ & $39,8 \pm 2,1$ \\
\hline group & $0,95 \pm 0,07$ & $43,1 \pm 2,2^{*}$ \\
\hline group & $1,24 \pm 0,08$ & $54,8 \pm 2,4^{*-*}$ \\
\hline group & $1,18 \pm 0,11$ & $36,0 \pm 2,3$ \\
\hline
\end{tabular}

Table 3: The size of the corpus luteum of pregnancy and the length of the embryo and fetus in the prevention of early embryogenesis disorders in cows, $\mathrm{mm}$

\begin{tabular}{|c|c|c|}
\hline \multirow[t]{2}{*}{ Group } & \multicolumn{2}{|c|}{ Days of pregnancy } \\
\hline & $30-32$ & $60-65$ \\
\hline \multicolumn{3}{|c|}{ The size of the corpus luteum } \\
\hline 1 group & $16,5 \pm 1,1^{*}$ & $22,9 \pm 1,6$ \\
\hline 2group & $19,7 \pm 1,3^{* *}$ & $27,1 \pm 1,2^{* *}$ \\
\hline 3 group & $14,9 \pm 0,9$ & $20,7 \pm 1,2$ \\
\hline 4 group & $18,5 \pm 0,9^{*}$ & $25,4 \pm 1,5^{*}$ \\
\hline 5 group & $19,2 \pm 1,2^{* *}$ & $26,5 \pm 1,7^{* *}$ \\
\hline 6 group & $13,9 \pm 0,8$ & $18,8 \pm 1,1$ \\
\hline \multicolumn{3}{|c|}{ Crown-rump length of fetus } \\
\hline 1 group & $18,7 \pm 1,1^{* *}$ & $55,7 \pm 3,9$ \\
\hline 2group & $20,5 \pm 1,2^{2+*}$ & $74,2 \pm 4,8^{n+*}$ \\
\hline 3 group & $17,9 \pm 1,1$ & $54,1 \pm 4,1$ \\
\hline 4 group & $20,7 \pm 1,1^{*+*}$ & $69,4 \pm 3,7^{+\cdots+\infty}$ \\
\hline 5 group & $23,7 \pm 1,3^{ \pm= \pm}$ & $75,6 \pm 5,3^{\operatorname{man}}$ \\
\hline 6 group & $15,1 \pm 0,7$ & $49,2 \pm 2,1$ \\
\hline
\end{tabular}

The use of prolonged form of progesterone - progestamag provides an increase in the size of the corpus luteum of pregnancy, which is $19.9 \%$ more in 30-32 days compared with the use of progesterone and by $41.7 \%(\mathrm{P}<0.01)$ than in the negative control, at 60-65 days of gestation, respectively, by 18.3 and $44.1 \%(\mathrm{P}<0.01)$.
The use of gonadotropic follymag in the first days after insemination contributes to an increase in the size of the corpus luteum of pregnancy compared with intact animals in 30-32 days of gestation by 7.2\%, in 60-65 days of pregnancy - by $10.1 \%$. The combined use of follymag and selemag is accompanied by an increase in the size of the corpus luteum, which is $33.1 \%(\mathrm{P}<0.05)$ more than the negative control in 30-32 days of gestation, and in 60-65 days - by $35.1 \%$, respectively $(\mathrm{P}<0.05)$.

Triple administration of bovine recombinant interferon-tau is accompanied by an increase in the corpus luteum, whose size exceeds the same in $30-32$ days by $38.1 \%$ $(\mathrm{P}<0.01)$ compared to the negative control, and by 40.9 in $60-65$ days $\%(\mathrm{P}<0.01)$.

An increase in the size of the corpus luteum of pregnancy had a beneficial effect on the size of the developing embryo and fetus.

Exogenous administration of progesterone in the early stages of pregnancy had a positive effect on the development of the embryo and fetus, which was manifested by an increase in length of $13.2-23.8 \%(\mathrm{P}<0.01)$ in comparison with the negative control. The use of a prolonged progestamag provided an increase in the crown-rump lengthin comparison with intact animals by $35.8-50.8 \%(\mathrm{P}<0.001)$. The use of follymag alone led to an increase in the length of the embryo and fetus in comparison with the negative control by $9.9-18.5 \%$, and in combination with the selemag by $37.1-41.1 \%(\mathrm{P}<0.001)$.

The use of bovine recombinant inteferferon-tau resulted in an increase of the crown-rump lengthcompared to intact animals by $53.7-56.9 \%(\mathrm{P}<0.001)$.

Thus, the use of progestagam, follymag in combination with selemag and interferon-tau had the greatest influence on the morphometric indicators of the corpus luteum of pregnancy and the size of the embryo and fetus, respective$1 y, 33.1-44.1 \%$ and $35.8-56.8 \%$ more than intact animals. 
Table 4: The incidence of cows during parturation, the postpartum period and the condition of newborn calves after the use of biologically active drugs

\begin{tabular}{|lllllll|} 
Indicators & $\mathbf{1}$ group & $\mathbf{2}$ group & $\mathbf{3}$ group & $\mathbf{4}$ group & $\mathbf{5}$ group & $\mathbf{6}$ group \\
\hline Labor weakness, \% & 20,0 & 0,0 & 16,7 & 12,5 & 0,0 & 25,0 \\
\hline Retention of placenta, \% & 20,0 & 14,3 & 16,7 & 12,5 & 0,0 & 25,0 \\
\hline Acute subinvolution of uterus, \% & 40,0 & 14,3 & 33,4 & 25,0 & 16,7 & 50,0 \\
\hline Acute endometritis, \% & 40,0 & 28,6 & 33,4 & 37,5 & 33,3 & 50,0 \\
\hline Fetal weight, кг & $31,2 \pm 1,7$ & $33,8 \pm 1,8$ & $29,8 \pm 1,2$ & $35,4 \pm 2,1^{*}$ & $33,7 \pm 1,9$ & $30,7 \pm 1,3$ \\
The incidence of diarrhea in newborn calves, \% & 40,0 & 28,6 & 16,7 & 12,5 & 16,7 & 50,0
\end{tabular}

Remark: ${ }^{*}-\mathrm{P}<0,05 ;{ }^{*}-\mathrm{P}<0,01 ;{ }^{-4}-\mathrm{P}<0,001$

Noted changes in the period of early embryogenesis when biologically active preparations are used by animals ultimately reflected on the state of the newborn young cattle (Table 4).

After progesterone was used, weakness of labor, retention of afterbirth, acute subinvolution of the uterus and acute postpartum endometritis and the incidence of diarrhea in calves were diagnosed 1.3 times less than in the negative control. At the same time, no significant differences were found in the fetal weight in cows of the experimental and control groups.

In cows, after using a prolonged agent, progestamag, the retention of the placenta, acute subinvolution of the uterus and acute endometritis are diagnosed 1.5 times less frequently, compared to animals from the negative control group. The fetal weight obtained from cows treated with progestamag is $10.1 \%$ more than that produced from intact animals, with a decrease in cases of diarrhea by 1.75 times. After the combined use of follymag and selemag, the pathology of the parturation and the postpartum period was diagnosed 1.3-2.0 times less, while the number of cases of diarrhea in calves was reduced by 4.0 times. The fetal weight obtained from these cows is $15.3 \%(\mathrm{P}<0.05)$ more compared to the negative control.

Triple application of bovine recombinant interferon-tau is accompanied by the absence of cases of parturation pathology and reduction of the pathology of the postpartum functional and inflammatory period by $1.5-3.0$ times. The mass of fetuses born from cows after being treated with interferons is $9.8 \%$ more than in the negative control, with a reduction in the diagnostics of diarrhea syndrome in them by 3.0 times.

\section{CONCLUSION}

Thus, the syndrome of delayed embryo development is recorded on average in $36.7 \%$, and intrauterine death - in $18.5 \%$ of fertilized animals.
The most effective ways of preventing disorders of early embryogenesis (fetal death, embryo and fetal growth retardation syndrome) are the use of progestogenic and gonadotropic drugs, as well as interferon-series drugs - interferon-tau. The prophylactic efficacy of progestamag was $60.0 \%$, follymag combined with selemag $61.5 \%$, and bovine recombinant interferon-tau $66.7 \%$.

The use of progestamag, bovine recombinant interferon-tau, or the combined use of follymag and selemag helps to reduce the incidence of intrauterine embryo death by 1.5-1.8 times compared with the negative control and the embryo-fetal growth retardation syndrome - 3.0-3.7 times. Pregnancy after the application of these funds proceeds against the background of increased content of progesterone (higher by 16.4-52.2\%), which favorably affects the development of the embryo and fetus, the length of which in the first two months of gestation is $35.8-56.9 \%$ more than intact animals.

The use of a prolonged progestamag for the prevention of disorders of embryonic development is accompanied by a certain weakening of the inflammatory reaction, a decrease in endogenous intoxication and an increase in the activity of the antioxidant system; the combined use of the gonadotropic drug follymag and selenium containing agent selemag - by activating the indices of the general nonspecific resistance of the organism of pregnant animals; triple application of bovine recombinant interferon-tau - activation of the enzymatic and non-enzymatic antioxidant defense, humoral and cellular link of the body's natural resistance while reducing the processes of lipid peroxidation and endogenous intoxication of the organism.

\section{ACKNOWLEDGEMENTS}

This paper was financially supported by the Ministry of Education and Science of the Russian Federation on the program to improve the competitiveness of Peoples' Friendship University of Russia (RUDN University) among the world's leading research and education centers in the 2016-2020. 


\section{CONFLICT OF INTEREST}

We declare that authors have no competing interests.

\section{AUTHORS CONTRIBUTION}

The authors contributed equally.

\section{REFERENCES}

- Baitlesov EU (2007). Test of progesterone as a means to reduce embryonic mortality. Vet. Pathol. 2(21): 231-233.

-Bonadonna T (1969). Genetic study of fertility and infertility of farm animals. M., 1969. - 40 p.

- Basavaraja R, Przygrodzka E, Pawlinski B, Gajewski Z, Kaczmarek MM, Meidan R (2017). Interferon promotes luteol endothelial cell survival and inhibits specific luteolytic genes in bovine corpus luteum. Reproduction. 154(5): 559568. https://doi.org/10.1530/REP-17-0290

-Brooks K, Burns G, Spencer TE (2014). Conceptus elongation in ruminants: roles of progesterone, prostaglandin, interferon tau and cortisol. J. Anim. Sci. Biotechnol. 5(1): 53. https:// doi.org/10.1186/2049-1891-5-53

- Chaudhary AK, Purohit GN (2012).Ultasonographic Detection of Early Pregnancy Loss in Dayri Cows. J Anim. Sci. Adv .2(8): 706-710.

- Chomaev AM, Kolodiev CB (2003). Fetal loss in cows. Vet. Med. 5: 15-17.

-Demmers RJ, Derecka K, Flint A (2001). Trophoblast interferon and pregnancy. Reproduction. 121: 41-49. https://doi. org/10.1530/rep.0.1210041

- Dulger GP (2012). Reproductive losses in cows during the parturation period. Vet. Med. Farm Anim. 11: 30-35.

-Ealy AD, Wooldridge LK (2017). The evolution of interferon tau. Reproduction. 154(5): 1-10. https://doi.org/10.1530/ REP-17-0292

- Forde N, Lonergan P (2017). Interferon-tau and fertility in ruminants. Reproduction.154(5): 33-43. https://doi. org/10.1530/REP-17-0432

- Hansen TR, Sinedino LDP, Spencer TE (2017). Paracrine and endocrine actions of interferon tau (IFNT). Reproduction. 154(5): 45-59. https://doi.org/10.1530/REP-17-0315

- Imakawa K, Bai R, Nakamura K (2017). Thirty years of interferon-tau research; Past, present and future perspective. J. Anim. Sci. Technol. 88(7): 927-936. https://doi. org/10.1111/asj.12807

- Kose M, Kaya MS, Aydilek N (2016). Expression profile of interferon tau-stimulated genes in ovine peripheral blood leukocytes during embryonic death. Theriogenology. 85(6): 1161-1166. https://doi.org/10.1016/j. theriogenology.2015.11.032

-Klinsky YD, Chomaev AM., Ogulov AO (1987). The use of a surfagon to increase the fertility of cows. Livestock.1: 47-48.

-Lamming GE, Wathes DC, Flint APF, Payne JH, Stevenson KR, Vallet JL (1995). Local acton of trophoblast interferons in suppression of the development of oxytocin and oestradiol receptors in ovine endometrium. J. Reprod. Fertility. 105: 165-175. https://doi.org/10.1530/jrf.0.1050165

-Lenchenko E, Lozovoy D, Strizhakov A, Vatnikov Y, Byakhova V, Kulikov E, Sturov N, Kuznetsov V, Avdotin V, Grishin V (2019). Features of formation of Yersinia enterocolitica biofilms. Vet. World. 12(1): 136-140. https://doi. org/10.14202/vetworld.2019.136-140

-Lenchenko EM, Vatnikov YA, Sotnikova ED, Kulikov EV, Gnezdilova LA, Seleznev SB, Strizhakov AA, Kuznetsov VI (2017). Experimental toxemia of chickens contaminated with yersinia enterocolitica bacteria. Asian J. Pharmaceut. 11(1): S91-S96.

-Lyalichkina NA, Peshev LP, Balchenkova YP, Shchukin LP (2012). The value of endogenous intoxication in the pathogenesis of placental insufficiency with threatened abortion and extragenital diseases in pregnant women. Fund. Res. 12(1): 96-99.

-Milovanov VK, Sokolovskaya II (1984). Ways to eliminate losses in the process of reproduction of dairy cattle. In: Theory and practice of animal reproduction. M.: Kolos. 47-68.

- Retzky MI, Shakhov AG, Shushlebin VI (2005). Guidelines for the diagnosis, treatment and prevention of metabolic disorders in productive animals. Methodical recommendations. Voron. $86 \mathrm{p}$.

- Romano JE, Thompson JA, Kraemer DC, Westhusin ME (2007). Early pregnancy diagnosis by palpation per rectum: Influence on embryo/fetal viability in dairy cattle. Theriogenology. 67: 486-493. https://doi.org/10.1016/j. theriogenology.2006.08.011

- Safonov VA (2011). Adaptive changes in the antioxidant and hormonal status in cows. Vet. Med. 6: 32-33.

-Seleznev SB, Kulikov EV, Vetoshkina GA, Vatnikov YA, Sotnikova ED, Krotova EA, Yagnikov SA, Yakunina MN (2017). The evolution and structural organization of the organs of vertebrate immune system. Asian J. Pharmaceut.11(1): S84-S90.

-Shakhov AG, Masyanov YN, Retzky MI (2005). Guidelines for the evaluation and correction of the immune status of animals. Methodical recommendations. Voronezh. 116 p.

- Shirasuna K, Matsumoto H, Matsuyama S, Kimura K, Bollwein H, Miyamoto A (2015). Possible role of interferon tau on the bovine corpus luteum and neutrophils during the early pregnancy. Reproduction. 150(3): 217-225. https://doi. org/10.1530/REP-15-0085

- Spencer TE (2007). Pregnancy recognition and conceptus implantation in domestic ruminants: roles of progesterone, interferon and endogenous retroviruses. Reprod. Fertil. Develop. 19: 65-78. https://doi.org/10.5661/RDR-VI-379

- SpenserTE,HanserTR (2015).Implantation and Establishment of pregnancy in ruminants. Adv. Anat. Embryol. Biol. 105135. https://doi.org/10.1007/978-3-319-15856-3_7

- Suleymanov SM, Usha BV, Vatnikov YA, Sotnikova ED, Kulikov EV, Parshina VI, Bolshakova MV, Lyshko MU, Romanova EV (2018). Structural uterine changes in postpartum endometritis in cows. Vet. World.11(10): 14731478. https://doi.org/10.14202/vetworld.2018.1473-1478

-Tefera M, Chaffaux S, Thibier M, Humblot P (2001). Lack of effect of post-Al hCG or GnRH treatment on embryonic mortality in dairy cattle. Livest. Prod. Sci. 71(2-3): 277-281 https://doi.org/10.1016/S0301-6226(01)00213-5.

-Wu G, Bazer FW, Wallace JM (2006). Board-invited Review; Intrauterine growth retardation; Implications for the animal sciences. J. Anim. Sci. 84: 2316-2337. https://doi. org/10.2527/jas.2006-156

-Zhao L, Chen YH, Wang H (2008). Reactive oxygen species contribute to lipopolysaccharide-induced teratogenesis in mice. Toxicol. Sci. 103(1): 149-157. https://doi.org/10.1093/ toxsci/kfn027 